\title{
LA ALTERNANCIA POLIITCA EN BAJA CALIFORNIA: HACIA UN NUEVO EQUILIBRIO DE PODERES
}

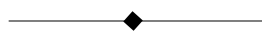

\section{RESUMEN}

Desdequeel Partido Acción N acional triunfó en las elecciones para gobernador en el estado deBaja California en 1989seinauguró en México la alternancia política en una gubernatura, con ello serompió el mito dequeera imposiblepara el PRI compartir el poder a ese nivel. Los escasos espacios ganados o cedidos por el mismo partido en el poder, sirvieron para quela oposición confrontara y criticara la centralización del poder y la neutralización de la representación, es decir, más que ofertar a sus electores discursos nacionalistas, los partidos de oposición abanderaron los resentimientos anticentral istas del norte del país en particular, y desacreditaron la relación viciada entreel legislativo y el ejecutivo tanto a nivel federal como estatal. Deacuerdo con estas consideraciones, en esteensayo seexploran las posibilidades de fundar una nueva relación horizontal y vertical entre poderes en el estado de Baja California, gobernado por el Partido Acción Nacional en los últimos diez años.

\section{A BSTRACT}

Ever sincetheN ational Action Party (PAN) won thegovernor elections in the State of Baja California in 1989, Mexico experienced theinauguration of a political alternation in a governor's office, which brought about the smashing of the myth that it was impossible for the PRI to share power at that level. The scarce forums won or surrendered by the party ever present in power, allowed theopposition to confront and criticize the centralization of power and the neutralization of representation, that is, rather than offering its voters nationalistic discourses, theopposition parties joined the cause of the anti-centralist resent, particularly present in the northern part of the country, and discredited the decaying relationship between thelegislative and the executive powers (the presidency), both at a federal and states levels. In view of these considerations, the possibilities of setting the foundations for a new horizontal and vertical relationship among powers in the state of Baja California, which during thelast ten years has been governed by the N ational Action Party, are discussed in this essay.

\footnotetext{
* maestro de la facultad de CIencias sociales y politicas de la uABC. Correo electrónico: cspoldoc@hotmail.com
} 


\section{INTRODUCCIÓN}

Desde que el Partido Acción Nacional (PAN) triunfó en las elecciones para gobernador en el estado de Baja California en 1989, en México se inaugurólaalternancia política en unagubernatura, y con ello serompió el mito dequeera imposiblequeel Partido Revolucionario Institucional (PRI), quehasta entonces era el partido oficial a nivel estatal, compartiera el poder en esenivel. Si bien es cierto, antes deesa fecha el mismo PAN y otros partidos habían conquistado al cal días o curules en los congresos federal y local es, estas posiciones eran espacios limitados en dondeel origen fundamental del acceso a esas instancias provenía ya fuera de una negociación pre o poselectoral, o de los mismos espacios que el régimen cedía antelas presiones social es y la necesidad depluralizar y dinamizar el anquilosado sistema departido hegemónico que deterioraba la vitalidad federalista y republicana de las instituciones. Esos espacios derepresentación popular abiertos a la oposición fueron utilizados para confrontar y criticar la centralización del poder y la neutralización de la representación; es decir, más que ofertar a sus electores discursos nacionalistas, los partidos de oposición -y sobre todo el PAN - supieron abanderar los resentimientos anticentralistas del nortedel paísen particular, y desacreditar la relación ya muy viciada entrelos poderes legislativo y ejecutivo, tanto a nivel federal como estatal.

De acuerdo con estas consideraciones, en este ensayo se exploran las posibilidades de fundar una nueva relación horizontal y vertical entrepoderes en el estado deBaja Cal ifornia, gobernado por el Partido Acción Nacional en losúltimos diez años.

La dinámica de los gobiernos divididos (para el caso de Baja Cal ifornia) debecorregir, al igual queen nivel federal, la preeminencia del ejecutivo sobreel legislativo, y revital izar la autonomía municipal. Una de las tesis centrales del PAN es la descentralización como medio para el fortalecimiento de la democratización nacional, y con ello se intenta acabar con la cultura y prácticas presidencialistas. Sin embargo, a quienes observamos el proceso democratizador en el estado nos preocupa quela anhelada al ternancia no quede tan sólo en un cambio del personal político y en la aplicación de nuevas formas de gestión administrativa. Es deseable quela al ternancia política corrija los vicios 
no agotados del presidencial ismo queseextienden alos gobiernos locales; y que ésta sea el mejor medio para vincular la toma de decisiones entre diversos grupos sociales. También independientementedel partido que controlela mayoría parlamentaria, losgobiernosmunicipal es y el poder ejecutivo, es necesario armonizar y equilibrar las relaciones de coordinación y cooperación en contextos de gobiernos divididos. Pero sobre todo, es deseable que el PAN contribuya al ejercicio pleno de un sistema presidencial regido por la lógica de los balances y contrapesos.

Este trabajo aborda la relación existente entreel poder ejecutivo y el legislativo, considerando que el gobierno panista presume regirse por principios democráticos que harán posible la eliminación de la subordinación delos legisladoresal gobernador, la obediencia servil de los alcaldes, y el disciplinamiento total a las decisiones del gobernador.

La alternancia política (protagonizada por el PAN) es identificada como la posibilidad de modificar los ritos y códigos adoptados del presidencialismo en los gobiernos estatales, sin que por ello se sacrifiquela unidad y fortal eza partidista. Una verdadera reforma en el sistema político mexicano con nuevas prácticas y esquemas de funcionamiento parece nacer desde los gobiernos locales venciendo un sinnúmero deobstáculos einercias institucionales. Éstas son, pues, las coordenadas del presente trabajo.

\section{LASPRÁCTICASY RITOSDEL PRESIDENCIALISMO EN LOSGOBIERNOSLOCALES}

El sistema político mexicano surgido del pacto político de 1929,1 permitió eliminar el recurso dela armas en la disputa por el poder y desactivar a grupos y movimientos disidentes que amenazaban la estabilidad políticay, además, posibilitóla unidad y conciliación nacional, pero ello

${ }^{1}$ Para el autor los puntos básicos del pacto de 1929 son a) el partido es el único acceso al poder político en México; b) el jefe máximo de la revolución es el árbitro indiscutible en todas las disputas políticas; c) la jefatura máxima del partido y la presidencia se identifican y consolidan en la figura del ejecutivo, y d) el poder del presidente está estrictamente limitado a su periodo constitucional de seis años. (Blum, 1996). 
a cambio desubordinar a los diversos grupos depoder local a través del control delos recursos fiscales y de las lealtades al presidente en turno.

Como las expectativas de promoción política y ascenso social del conjunto de la clase política quedaron en manos del presidente, los gobernadores avalaban, defendían y difundían los proyectosy políticas del centro, sin que existiera en ello la más mínima defensa de la autonomía de los estados y el respeto al sistema federal. Precisamente, como el sistema político funcionabaal margen delas normas einstituciones formales, las reglas no escritas sustituyeron la vigencia del estado de derecho, concentrándose en el ejecutivo poderes inscritos en la Constitución y los derivados de las reglas informales del pacto de 1929.

La defensa de la soberanía y la unidad nacional se utilizaron para limitar los márgenes de acción entre los gobiernos estatales evitando cualquier posible alianza de gobernadores rebeldes al centro. Así, la autonomía delos estados quedó reducida a un si mbólico ejercicio delas pocasfacultades quela Constitución no prohibió a los gobiernos locales.

El sistema federal se canceló, pues la concentración de los poderes presupuestales en una persona derivó en un hombrefuerte capaz de instrumentar dentro de un amplio programa degobierno las políticas económicas y sociales queredujeran los grandes rezagos sociales, crear la infraestructura física necesaria para impulsar el crecimiento, y medianteuna activa participación del estado en la economía, disolver los nudos estructurales del subdesarrollo.

Todo este accionar estatal quedó vinculado al desempeño sexenal del presidente en turno, por lo que hoy pervive el culto a los personal ismos como forma moderna del caudillismo; es decir, la figura del caudillo seinstitucionaliza con el cargo, pero no desaparece, por el contrario, el ejedearticulación con los diversos grupos depoder hace que se extienda y reproduzca el culto a la figura del presidente, sintetizándolo como el gran benefactor ante las masas, como el gran elector (transmisor y árbitro en la lucha por el poder) dentro de la coalición revolucionaria, y como el gran conciliador entrelos diversos grupos depresión.

Por todo ello, desde el surgimiento del Estado de la revolución, el presidente dela república ha sido mucho más queun ejecutor, pues le ha correspondido organizar a grupos sociales (de trabajadores o 
económicos), promover proyectos de desarrollo, definir el rumbo económico, conducir la política educativa, resolver acerca delasformas de propiedad, arbitrar conflictos sociales, representar al país en el exterior, modificar la Constitución, regular la lucha política, intermediar entre distintos intereses, etcétera. De ahí el carácter exacerbado del presidencialismo mexicano. (Espinoza Toledo, 1996).

Estas tres funciones centrales (gran benefactor, gran elector y gran conciliador) seejercieron con mayor vigor y funcionalidad mientras se mantuvo inalterado el monopolio de acceso al poder (1929-1988); duranteesteextenso periodo la concentración depoderes selogró con baseen la transferencia de lealtad es que los otros poderes depositaron en un hombre. La condición de mantener inalterado el acceso privilegiado al poder dela coalición fueel fundamento para cohesionarseen torno al hombrequecada seis años ocupaba el cargo sin graves fisuras, desacato eindisciplina.

El presidente es árbitro incuestionado, aunque no neutral, en las disputas entre los distintos componentes del partido oficial, casi la totalidad de los actores incluidos en el sistema político. La aceptación de la autoridad presidencial como última instancia de los conflictos permitió mantener la disciplina entre los diversos grupos políticos locales y nacionales, a los que se abría una perspectiva de largo plazo, gracias a la garantía del relevo presidencial. (Romero, 1996).

El sistema político mexicano decortepresidencial seedificó con gran éxito reduciendo al máximo la natural eza friccional entre los poderes legislativo y ejecutivo que caracteriza, precisamente, a un sistema presidencial. La clave del éxito residió en la hegemonía de un partido y la sumisión de los representantes populares surgidos del mismo partido del presidente.

Los ritosy prácticas del presidencialismo seextendieron con diversas modal idades sexenales en la total idad de los estados gobernados por la coalición revolucionaria, y el gobernador desempeñó las mismas funciones de benefactor social, el ector político y conciliador social en su respectivo feudo estatal. 
El presidencialismo mexicano, como forma alterada del sistema presidencial, sustituyólaarquitectura institucional propia deun sistema debalances y contrapesos, por un esquema dealianzas y pactos fluidos y coyunturales que solidificaron las estructuras corporativas y elitistas.

\begin{abstract}
"Para convertirse en una instancia concentradora de poder, el ejecutivo hubo de penetrar y subordinar al resto de las estructuras políticas previstas en la Constitución; esto es anular los centros de poder que, a través de su acción autónoma, pudieron haber compartido y contrabalanceado el poder ejecutivo" (Casar, 1996).
\end{abstract}

Ello determinó queel presidenteseconvirtiera en el engranajecentral dela política mexicana, pero con una flexibilidad asombrosa para que el sistema político se autorreparara y regenerara al cambiar la correlación defuerzasal interior del bloqueen el poder cada seis años.

\begin{abstract}
Por un Iado, Ia utilización de las Ilamadas facultades metaconstitucionales no ha dependido de la voluntad exclusiva del presidentedela república, sino dela obediencia del conjunto de dirigentes y líderes asociados al poder y del manejo político quecada gobernantees capaz dellevar a cabo. En otras palabras, no se trata de una serie de facultades que se entreguen en paquete y mecánicamente con el cambio de mandos, sino de un juego de fuerzas y de intercambios recíprocos con los dirigentes de las distintas organizaciones querespaldan la figura presidencial. (EspinozaToledo, 1996).
\end{abstract}

Es decir, los componentes democráticos vigentes en un sistema representativo y los fundamentos de legitimidad de acceso al poder, así como el respeto al estado de derecho, fueron reemplazados por una seriedenormas einstituciones informal es queservían para garantizar la disciplina de los diversos actores políticos. La cohesión y coherencia del sistema político quedó así determinada por la observancia de las reglas no escritas, y no por el respeto al marco constitucional y el derecho. Estas prácticas, ritos y reglas no escritas del sistema político 
mexicano se aplican, en mayor o menor medida, por parte de los gobernadores; la posible permanencia, desuso y sustitución de esas prácticas en aquel los estados donde se ha dado la alternancia, posibilita la desaparición del autoritarismo en nuestro país.

Los estudios de diversos politólogos y juristas hacen énfasis en diversos factores que convergen en la desviación del sistema presidencial en México: el presidencialismo, quecon el uso del término denota la exacerbación del poder y el ejercicio autoritario del mismo. En el cuadro 1 se sintetizan los factores central es que consolidaron el presidencial ismo, retomados de escritos clási cos como La formación del poder político en M éxico, deA rnaldo Córdova; R eforma al sistema político mexicano, de Luis Rubio; El presidencialismo mexicano, de JorgeCarpizo, y La formación del sistema político mexicano, deVíctor López Villafañe.

La fundación del estado posrevolucionario se dio con la promulgación dela Constitución de1917. En ella seestableceel tipo degobierno que se constituye, definiéndose como una república representativa, democrática y federal unida por estados libres y soberanos. Sin embargo, la supresión de estos rasgos institucionales se logró con relativa facilidad, ya que, por medio de una alianza política en 1929 , se creó un sistema dearregl os y pactos quefortalecieron la central ización del poder en un hombre, que paradójicamente debía cumplir con los preceptos constitucionales; es decir, queel presidencial ismo mexicano no es un fenómeno anticonstitucional, sino proconstitucional .

Esta extraña paradoja complicó aún más la dinámica del sistema político mexicano, ya que las normas e instituciones informales o el estado dederecho prevalecían a discreción delosintereses del ejecutivo. Si se necesitaba solucionar controversias entre gobiernos estatales y afectar intereses particulares, seaplicabala ley y sedirimían los asuntos demanera institucional; pero si se requería suprimir o limitar a grupos políticos locales o destituir a personajes no gratos, se accionaban las instituciones informales y las reglasno escritas. También las recompensas y promociones personales dentro dela familia revolucionariatenían como parámetros desu actuación la discrecionalidad del presidente.

En México, la notable y ampliamente reconocida dificultad analítica que presenta su sistema político parece tener su 
origen en la especial relación queexisteentrelas instituciones formales y las informales, entrelas normas escritas y aquéllas no escritas y, que sin embargo en su conjunto, determinan día con día las conductas válidas posibles detodos los actores del sistema, a tal grado que pareciera que las normas e instituciones formales funcionan principalmente para asegurar el funcionamiento en la realidad de las normas e instituciones informales (Blum, 1996).

La función central de los individuos vinculados a esta dinámica autoritaria fue, precisamente, ampliarla y reproducirla, pero con una serie de variantes personal es en la conducción deun gobierno estatal; es por ello que, podemos identificar la reproducción de los ritos y prácticas políticas calcadas del nivel federal a nivel degobierno estatal, simpley sencillamenteporque, hasta haceunos pocos años, el conjunto dela clasegobernanteaún pertenecía a una misma filiación partidista (ver cuadro 2).

Además, el esquema de relación subordinada de partidoejecutivo se reproduce a nivel local: el poder de designación de candidatos a presidentes municipales, diputados locales y funcionarios del partido es facultad del gobernador; ello se traduceen la preeminencia del poder ejecutivo sobre los otros poderes: es un presidencialismo regional (Espinoza Valle, 1998:53-54).

Por prácticas políticas entendemos la ejecución deuna seriedereglas propias del sistema político derivadas del pacto político de 1929, y el término rito lo usamos para diferenciar los valores políticos y sociales delos individuos; es decir, las prácticas son la reproducción colectiva en la ejecución de las reglas, y el rito es la interiorización individual que legitima los códigos subyacentes de intercambios de activos.

Paraser más claros: una práctica política central en el sistema político mexicano fue la de no oponerse a ninguna decisión presidencial por parte de los legisladores prisitas; el rito, en cambio, es el valor de la disciplina que legitima la acción, ya que a cambio de la sumisión ante 


\section{CUADRo 1. Causas del presidencial ismo en México.}

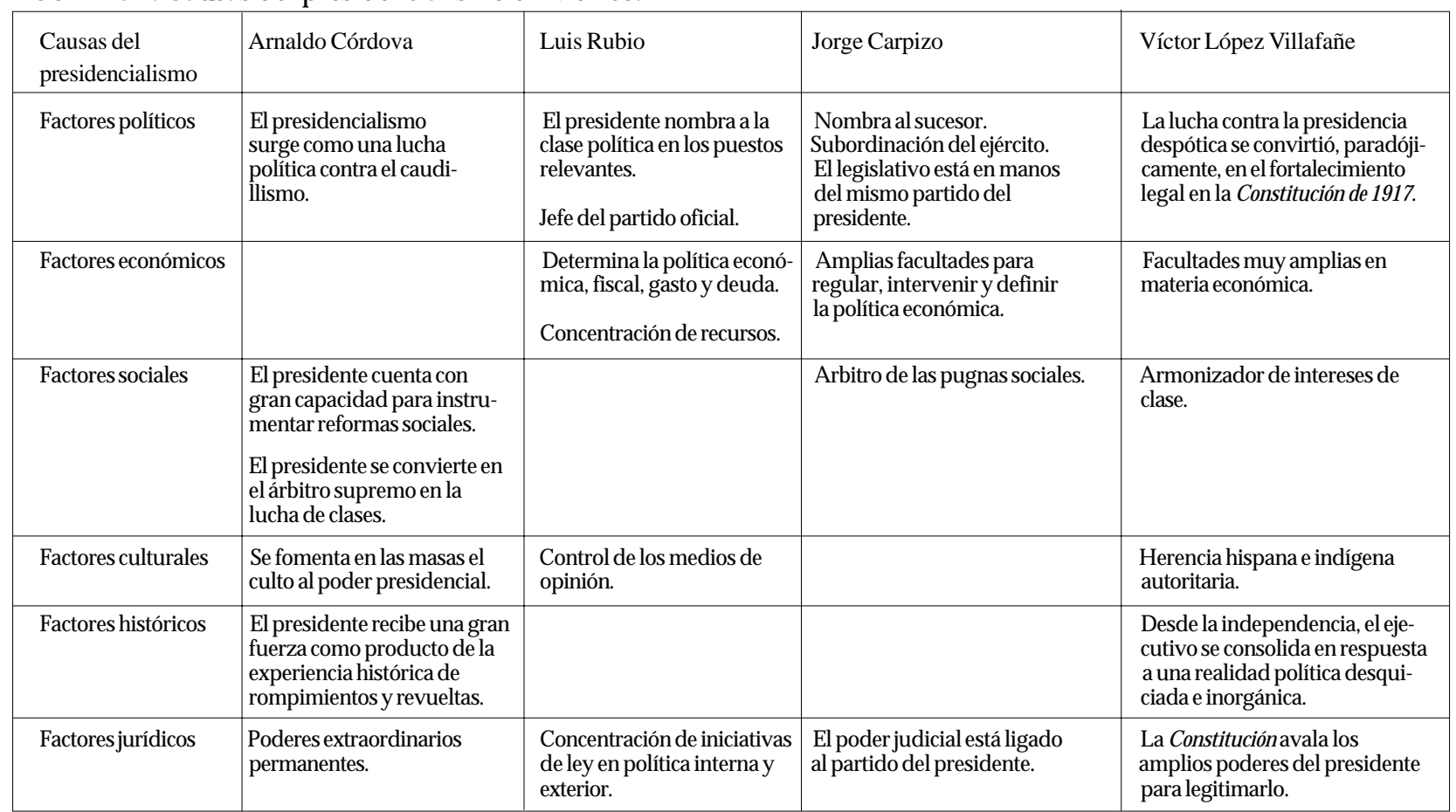

FuentE: Elaboración propia. 
CUADRO 2. Imitación del presidencialismo y subordinación de los gobiernos estatales.

\begin{tabular}{|c|c|}
\hline Presidentedelarepública & Gobernadoresemanadosdel PRI \\
\hline Jefenato del partido oficial. & Máximo lider del partido en el estado. \\
\hline $\begin{array}{l}\text { Nombray controla los principales cargos } \\
\text { delaadministración pública; promueve } \\
\text { ofrena las carreras políticas delos } \\
\text { legisladoresy gobernadores. }\end{array}$ & $\begin{array}{l}\text { Designaa losintegrantes desu gabinete, } \\
\text { nombraal presidentedel partido a nivel } \\
\text { estatal, y determina los méritos para la } \\
\text { ocupación decargoselectorales locales, } \\
\text { alcaldíasy diputaciones. }\end{array}$ \\
\hline Designa asu sucesor. & $\begin{array}{l}\text { Participa en conjunto con el presidentedela } \\
\text { república en la designación del candidato } \\
\text { agobernador. }\end{array}$ \\
\hline $\begin{array}{l}\text { Fungecomoárbitroy conciliador } \\
\text { entrelos diversos grupos depoder del } \\
\text { PRI y aquellos externosal partido. }\end{array}$ & $\begin{array}{l}\text { Seencarga decooptar losmovimientosso- } \\
\text { cialesy conciliar pugnas políticas deal cance } \\
\text { local; con ello puedeganar una promoción } \\
\text { política importante, ya queésta es, sin duda, } \\
\text { la cualidad más admirada en la cultura } \\
\text { política autoritaria. }\end{array}$ \\
\hline $\begin{array}{l}\text { El poder presidencial sehallalimitado } \\
\text { por el periodo constitucional del cargo. }\end{array}$ & $\begin{array}{l}\text { El poder deun gobernador seejerceaten- } \\
\text { diendo las directrices del poder central } \\
\text { (subordinación), pero reproduciendo los } \\
\text { viciosy cultura del presidencialismo. }\end{array}$ \\
\hline
\end{tabular}

FUENTE: Elaboración propia.

el presidente, se recibirá un activo (promoción a gobernador de su estado natal, por ejemplo).

Ahora, es importante preguntarnos si las funciones de control y subordinación ejercidas por los gobernadores emanados del PRI, cambiarán en las entidades federativas dondeel gobernador pertenece a otro partido. De continuar con dichas prácticas un gobierno estatal surgido delas filas dela oposición tradicional (PRI, PRD), el autoritarismo y los personalismos seguirán obstruyendo la democratización del sistema político mexicano.

Anteesto, ¿es posibleidentificar nuevas dinámicas entreel legislativo y el ejecutivo en BajaCal ifornia a partir del arribo al poder del Partido 
A cción Nacional?; ¿es adecuado limitar el peso político del gobernador en favor deun verdadero equilibrio de poderes?; ¿cómo cohabitan los gobiernos divididos surgidos del nuevo sistema de partidos competitivo? Estos temas serán abordados en el siguiente apartado.

\title{
COOPERACIÓN Y CONFLICTO: DINÁMICA DE LOSGOBIERNOSDIVIDIDOS
}

Con el triunfo panista en 1989, Baja California seconvirtió en el primer estado gobernado por un partido distinto al resto de los gobiernos estatales (de origen priista), y con ello surgió el primer gobierno dividido; es decir, por primera vez en la historia pol ítica posrevolucionaria el ejecutivo quedaba en manos del Partido Acción Nacional, junto con la mayoría legislativa. Sin embargo, no logró la mayoría absoluta, generándoseuna dinámica decooperación y conflicto entrelos poderes legislativo y ejecutivo.

\begin{abstract}
Así, el mapa político de la entidad, como resultado del proceso del 2 de julio de 1989, quedó configurado de la siguiente manera: además de la gubernatura, el PAN obtuvo las alcaldías de Ensenada y Tijuana, y en manos del PRI quedaron la capital (Mexicali) y Tecate. El congreso local quedaría integrado por nueve diputados del PAN, seis del PRI, uno del PARM, uno del PPS, uno del PFCRN y uno del PRD (Espinoza Valle, 1998).
\end{abstract}

Con estos resultados, la alternancia en el poder de un partido de oposición sehacía realidad a nivel degubernatura desde 1929. Deesta manera, sepudo atestiguar quela añorada democratización del sistema podía forjarseen las urnas, olvidándose al gunos actores agraviados y excluidos decual quier intención de cambio violento.

¿PERO QUÉ ES LA ALTERNANCIA POLÍTICA?

La alternancia política esla etapainicial del proceso de democratización y en ella confluyen el fin einicio de un régimen. En M éxico, el sistema electoral semicompetitivo y de partido hegemónico permitió la 
competencia partidista y la celebración de elecciones periódicas; sin embargo, no existía una verdadera competitividad partidista ni imparcial idad electoral.

Frente a este inequitativo orden, la democracia se equipara a tener elecciones regulares, conducidas limpiamentey con un conteo honesto. Sin embargo, es importante mencionar que por muy esenciales que sean las elecciones para un régimen democrático, no garantizan un sistema democrático.

Con la alternancia política en México, un sistema de partido semicompetitivo feneció y seconsolidó otro de mayor competitividad. Esto permiteconceptualizar laal ternancia política como la transferencia del poder entrepartidos quesesujetan a un orden legal einstitucional para gobernar, acatando siempre la voluntad popular expresada en las urnas. $Y$ aquí se presenta un aspecto muy característico de la alternancia política: la proliferación de partidos políticos hasta alcanzar un número abrumador. Si bien las expectativas y oportunidades de acceder al poder se abren, el hecho de que exista una mayor cantidad de partidos no significa que existe un sistema más democrático.

Igualmente, una democracia no se agota con la celebración de elecciones y la transparencia de los resultados; de hecho, con esta práctica se deben accionar variados mecanismos de representación y consenso; si estos mecanismos no aparecen con la alternancia política, la democratización se retardará o frenará.

Un sistema democrático debe ofrecer una variedad de procesos competitivos y canales para la expresión de los intereses y valores, tanto asociativos como partidarios, colectivos eindividuales, así como funcionales y territoriales.

Paraevaluar si en Baja California la alternancia política ha conducido a una democratización, es importante explorar nuevas dinámicas y mecanismos institucional es que rompan con la excesiva concentración del poder en el ejecutivo estatal , queserenuevey dignifiquela función legislativa, especialmente que el congreso cumpla sus funciones de control presupuestal y deproducción legislativa.

Con la al ternancia política en Baja Cal ifornia han aparecido nuevos tipos de gobierno que debemos abordar primero teóricamente determinando sus características y natural eza, con el fin devincularlo 
a las relaciones entre los poderes legislativo y ejecutivo que se observan en el marco de los gobiernos divididos en Baja California.

\section{¿QUÉ ESUN GOBIERNO DIVIDIDO?}

Para comprender la naturaleza de los gobiernos divididos es necesario enfatizar que son un producto típico de los sistemas presidenciales, en dondeexisteunaverdaderaseparación depoderes, además dequeinfluyen factores electorales, sociodemográficos y decompetitividad partidista.

Por gobierno dividido se entiende "aquél en que la mayoría de la cámara pertenecea un partid o y el presidente (o gobernador) a otro. Y al contrario, cuando un partido posee el control, tanto del ejecutivo como del legislativo, unicameral o bicameral, se habla de gobierno unificado, mientras que cuando nadie cuenta con mayoría (absoluta) congresional sehabla degobiernos no unificados" (Hurtado, 1998:46).

La estabilidad orgánica entreel legislativo y el ejecutivo federal, así como en nivel estatal, empieza a sustituirse por una dinámica de cooperación y conflicto resultado dela conformación plural del poder legislativo. En Baja California esta relación ha forzado alianzas congresionales a fin de imprimirle fluidez al proceso legislativo. Sin embargo, en todo sistema presidencial opera la lógica de obstrucción del legislativo (si es dominado por otro partido distinto al del gobernador para estecaso) haciaal ejecutivo; ello es producto del dilema de cooperar en el diseño de una política exitosa que capitalizará políticamenteel ejecutivo, en cambio, el fracaso político será compartido traduciéndose en menores índices de votación para el partido colaboracionista. Ello implica quelos costos de cooperar son muy al tos para un partido opositor quedesea precisamentemagnificar loserrores del ejecutivo, y así facilitar la futura derrota el ectoral del partido al que perteneceel gobernador.

El cuadro 3 muestra la composición partidista en el Congreso del Estado desde 1989. Observamos una configuración parlamentaria procliveal estancamiento y el obstruccionismo. Lacomposición delas legislaturas XIII, XIV y XVI seencuadran en el concepto de gobiernos no unificados, que son aquel los donde ningún partido político cuenta con mayoría absoluta (congresional). 
CUADRO 3. Composición de representantes políticos en el Congreso del Estado de Baja California, 1989-2001 (número dediputados por fracción parlamentaria).

\begin{tabular}{|l|c|c|c|c|}
\hline \multirow{3}{*}{ Partido político } & \multicolumn{4}{|c|}{ L eg i sl a t u r a } \\
\cline { 2 - 5 } & $\begin{array}{c}1989-1992 \\
\text { XIII }\end{array}$ & $\begin{array}{c}1992-1995 \\
\text { XIV }\end{array}$ & $\begin{array}{c}1995-1998 \\
\text { XV }\end{array}$ & $\begin{array}{c}1998-2001 \\
\text { XVI }\end{array}$ \\
\hline PAN & 9 & 9 & 13 & 11 \\
PRI & 7 & 10 & 11 & 11 \\
PT & 2 & & & \\
PRD & 1 & 3 & 1 & 3 \\
\hline
\end{tabular}

FUENTE: Elaboración propia con datos del Congreso del Estado.

La relación legislativo-ejecutivo en el estado de Baja California ha pasado de ser un esquema subordinado y disciplinado, a una relación de acuerdos y negociaciones volátiles y coyunturales. La parálisis institucional de gobiernos no unificados ha sido resuel ta mediante $\mathrm{e}$ cabildeo y negociaciones del ejecutivo con diputados de otros partidos para garantizar la gobernabilidad. Dehecho, la necesidad dealianzas y negociaciones obligó a Ernesto Ruffo durantesu mandato, a encontrar y fomentar el consenso en torno a temas de impacto social, ante una legislatura proclive al obstruccionismo; la gobernabilidad puedo ejercersecon una política deal ianzas centrada en laadhesión dealgunos diputados priistas a la fracción parlamentaria del PAN, mientras que legisladores de partidos pequeños (PARM, PPS, PFCRN) capital izaron su posición uniéndose al bloquepriista.

El esquema de gobierno no unificado que durante dicho periodo gubernamental sepresentó, requería de una alianza sólida. La peculiar adhesión dedos legisladores del PRI del sector campesino en apoyo al gobernador Rufffo A ppel, evidenció para muchos analistas una ágil maniobra del entonces presidente de la república, Carlos Salinas de Gortari. Con ello quedaron superados los supuestos de un sistema de partidos disciplinados, en donde resulta muy difícil llegar a tales al ianzas sin costos políticos que asumir. 
La falta de incentivos para cooperar en un gobierno dividido aumenta si existe un sistema de partidos polarizado ideológicamente y disciplinado. La orientación de los partidos nacionales que mayor peso tienen en la política local (PRI, PAN y PRD) parece confirmar esta premisa. ${ }^{2} A$ demás, el bajo incentivo para cooperar provienedeun juego de suma cero en que los partidos de oposición enfocan sus estrategias a la conquista del cargo del ejecutivo (estatal o federal). La tradicional desventaja o ineficiencia técnica del legislativo frente al ejecutivo ha fortalecido al gobernador, reproduciéndoselos esquemas desubordinación que se observan a nivel federal. La alternancia ha generando una mayor independencia, cuestionamiento y responsabilidad del legislativo ante la sociedad; sin embargo, todavía se carece de mecanismos institucionalesy legales quepermitan fortal ecer las capacidades técnicas de las legislaturas.

Para fortalecer el equilibrio horizontal entre el ejecutivo y el legislativo estatal, son necesarios cambios de carácter institucional y político, dondelos cambios decarácter institucional vienen a ser todos aquellos quemodifican las relaciones entreel ejecutivo y el legislativo; normalmente se tipifica en la elaboración de una constitución presidencial que establece una separación de poderes donde existen órganos con diversas funciones y legitimidad. Empero, la autonomíae independencia no seejercen a nivel operativo, ya quela normatividad introduce nexos interpoderes que significan dependencias y subordinaciones, especialmentedesdeel poder legislativo.

Por otra parte, los cambios decarácter político deben afectar estilos y prácticas añejas del sistema político, deorden electoral, de partidos, incluyendo factores detipo socioeconómico, dela cultura política y de la sociedad.

${ }^{2}$ A cerca de la dinámica del gobierno dividido y del sistema de partidos en México, recomendamos el ensayo deUlises Carrillo y A lonso Lujambio. "La incertidumbre constitucional. Gobierno dividido y aprobación presupuestal en la LVII legislatura del congreso mexicano, 1997-2000". Que puede ser consultado en internet en la siguiente página electrónica: htpp:/ / 132.248.82.108/ rms/ rms298/ carrillo.html 
Si bien es cierto que cada legislatura estatal cuenta con variados ordenamientosjurídicosy configuraciones políticas, estas recomendaciones se centran en la dinámica histórica de reproducción de la subordinación del legislativo anteel ejecutivo estatal, por ello también son aplicables al congreso federal .

Para consolidar la independencia del legislativo frenteal ejecutivo en el análisisy aprobación del presupuesto, en el control y fiscalización del gasto, y en el diseño coherente de iniciativas de ley, es necesario dotar al legislador de equipos de especial istas en políticas públicas e investigadores parlamentarios capaces de procesar, evaluar y emitir opiniones técnicas de la política económica y la ordenación del presupuesto, del destino y composición del gasto, y la aplicación de diagnósticos sectoriales que respalden y justifiquen las reformas o iniciativas deley.

En la medida en que prevalezca esta desventaja técnica entre el ejecutivo (administración pública) y el legislativo, seguirán ocurriendo escandalosos fraudes, cuentas secretas y discrecionalidad en la asignación del presupuesto. Tanto la incapacidad técnica y administrativa del legislativo evidencian el porqué para fiscalizar al gobierno en varias ocasiones se debe recurrir a auditorias privadas y consultorías deespecialistas erogándosegrandes sumas de dinero por dichos servicios.

El arribo de legisladores de partidos de oposición no es condición suficiente para garantizar la independencia del poder legislativo, se requiere de un equipo especializado dentro del congreso en cada legislatura conformada por asesores del más al to nivel académico.

Por otra parte, la capacidad de crítica y cuestionamiento del poder legislativo hacia el ejecutivo no se garantiza con el control de las asambleas con el arribo de partidos de oposición, sobre todo si el ejecutivo también perteneceal mismo partido que tienemayoría en el congreso. La capacidad legislativa del ejecutivo no significa mayor coherencia, sintonía y consenso en la creación de leyes. Si al sustituir a un gobernador de una afiliación política por otra se mantiene una mayoría parlamentaria del mismo partido del gobernador, secorre el riesgo de reproducir la relación subordinada entrelos dos poderes. "A partir de los elementos aquí expuestos, puede imaginarse la hipótesis 
de qué hubiera pasado de un congreso bajo el control absoluto del PAN. Es muy probable que su relación con el ejecutivo hubiera sido todavía más parecida que la actual relación que se establece entre el PRI y los congresos que domina" (Guillén, 1993:123).

Anteriormente, la relación de subordinación legislativo-ejecutivo (tanto a nivel federal como local) se entendía como el resultado del control delas carreras políticas de los diputados y senadores por parte del presidente(o del gobernador a nivel estatal). Sin embargo, el factor departido disciplinado-hegemónico determi nó queel nacientesistema de partidos en México se fundara en una disciplina rígida y una polarización ideológica. Es decir, a nivel local, la posibleperpetuación dela subordinación del legislativo anteel gobernador sepresenta como una condición de la disciplina del partido, y no como el producto del arreglo depromociones políticas personales.

Como primer elemento significativo tenemos que, a través del PRI, el presidentemantenía su intervención en los procesos de selección de candidatos a diputados y senadores. La mayoría de los legisladores debían su asiento en las cámaras al ejecutivo federal y no a los electores. Fue común que los candidatos seleccionados por el PRI tuvieran asegurado su escaño, una vez transcurridas las elecciones. Un segundo elemento fue la disciplina del partido. Los legisladores se hallaban disciplinados al presidente porque no tenían incentivos para actuar de manera contraria. La disciplina era la fórmula política que los diputados y senadores ejercitaron para dar continuidad a sus carreras políticas, puesto que se premiaba la disciplina y se castigaba la desobediencia. (Casillas, s/ f).

Anteestepanorama tenemos quela disciplina partidista rígida afecta arreglos institucionales en ambientes de gobiernos divididos. A nivel local, las fórmulas para impulsar acuerdos de gobernabilidad se han centrado en la negociación política del gobernador, tanto a legisladores desu propio partido como a los deoposición. Asimismo, la natural eza de partidos disciplinados ha mostrado tanto en los niveles federal y 
local, las dificultades para construir una exitosa relación entre el congreso y el ejecutivo, de allí que consideremos importante un relajamiento dela disciplina partidista con el fin degarantizar la crítica y el cuestionamiento al ejecutivo en turno, independientementedequé partido conserve la mayoría y el control en el congreso, así como la gubernatura. ${ }^{3}$

En otras palabras, sólo con la evolución hacia un sistema departidos menos disciplinados y menos polarizadosideológicamente, sealentará la crítica y el cuestionamiento (contrapeso y balance) al ejecutivo. La alternancia política y el pluralismo parlamentario en Baja California sólo desembocarán en una verdadera relación democrática entre el legislativo y ejecutivo si la votación en bloque es sustituida por un esquema másflexible decabildeo y patrocinio por partedel ejecutivo. Esta situación pondría fin a los acuerdos cupulares, la subordinación y la complicidad que acompañan a gobiernos unificados surgidos de partidos rígidamentedisciplinados.

En Baja California sehan presentado indicios deesta real idad entre la mayoría panista en el congreso y el gobernador, lo cual decepciona a los apologistas de la democracia y confunden a la sociedad. Si el sistema electoral y el sistema de partidos tienden a crear y concentrar mayorías divididas, se repetirá el control absoluto del gobierno en medio de una creciente polarización ideológica. Esto demostrará que el supuesto equilibrio depoderes no funciona con la alternancia política en Baja California.

Otro aspecto a observar en la búsqueda del equilibrio de poderes tienequever con la responsabilidad o rendición decuentas (accountability) por parte del ejecutivo y los legisladores. En el sistema de partido hegemónico las facultades fiscalizadoras, de evaluación y

${ }^{3}$ Para un enfoque integral entre sistema presidencial, sistemas de partido y condicionantes electorales que afectan la relación fluida y armoniosa delos sistemas presidenciales en América Latina, recomendamos: "El presidencialismo y los sistemas de partido en Latinoamérica", de Scott Mainwaring y Matthew Soberg Shugart, en La Reforma del Estado, unAM, México. 
cuestionamiento del poder legislativo no seejercieron - tanto en nivel federal como estatal - en tanto que la disciplina partidista y el control delas promociones políticas de los legisladores por partedel ejecutivo degeneraron en complicidad, corrupción e improvisación en la aprobación y control del gasto y en la mala formulación de las leyes.

Al presentarse a nivel local y nacional la alternancia política tanto en los gobiernos estatal es como municipales, así como en los congresos -tanto en nivel local y nacional-, es necesario garantizar la rendición decuentas. En la medida en que desapareceel monopolio deacceso al poder se reclama el fin dela corrupción eimpunidad. Sin embargo, un gobierno dirigido por partidos de oposición tendrá pocos incentivos en desarrollar procesos derendición decuentas, ya queal ser sustituida una mayoría por otra, es probable que lo que se inicie sea una cacería de brujas, ya que lo único que se buscará será evidenciar al gobierno saliente de vicios y corruptel as para aumentar las simpatías al partido alternantey asegurar mayores votos en elecciones futuras.

Y es así como surge la necesidad de un mecanismo de responsabilidad en el quetanto los legisladores y el gobernador sean sancionados por la ciudadanía, y dondela reel ección para gobernador y diputados auspiciaría dicha responsabilidad y mejoraría las habilidades técnicas y políticas de los legisladores. La reelección permitiría que tanto el legislador como el gobernador actuaran con compromiso social y probidad, pero, sobretodo, el elector tendría unaforma directa dehacer un juicio de la gestión gubernamental y del desempeño de sus legisladores; además, lepermitiría expresar y canal izar sus demandas por medio de congresistas con mayores vínculos sociales, fortal eciéndoseasí la representación popular.

En Baja California la dinámica política se ha transformado y pluralizado con lostriunfos electorales del PAN. La culturay las prácticas políticas que preval ecieron con anterioridad se han desgastado, tanto la actuación del legislativo, del ejecutivo y los gobiernos municipales se adecuan a las exigencias sociales y la competitividad electoral. Empero, modificar al gunos preceptos políticos posrevolucionarios como el de la no reelección, terminar con el excesivo centralismo (fiscal y político) y fortalecer a los gobiernos municipales, sólo será posible mediante una relación equilibrada y cooperativa tanto en el plano 
horizontal como en el vertical. La alternancia política, la crisis fiscal del estado y el agotamiento del presidencialismo son los detonantes de dichos cambios; sin embargo, en la construcción de un verdadero sistema presidencial de balances y contrapesos es necesaria una activa participación popular.

\section{CONCLUSIONES}

La alternancia política en Baja Cal ifornia así como en otros estados de la república, está alentando la democratización del sistema político mexicano. Al gradual ismo de la transición se le suma el local ismo de los avances democráticos; esto ha significado que en los estados gobernados por los partidos deoposición (PAN, PRD) aparezcan nuevas formas de gobernar en contradicción con los tradicionales acuerdos corporativo-clientelares delos gobiernos priistas.

En BajaCal ifornia la redistribución del poder (tanto en forma vertical como horizontal) abregrandes perspectivas decorrección del excesivo presidencialismo local; y así mantener un verdadero equilibrio de poderes. Esto implica también que los diputados aumenten su productividad legislativa y capacidad técnica en la formulación de leyes. Para lograrlo se recomienda un equipo de investigadores parlamentarios y expertos en políticas públicas como asesores de las distintas fracciones legislativas; además, sehace necesaria la reelección inmediata delos diputados para profesional izarlos y responsabilizarlos desus decisiones.

Por otra parte, la dinámica de los gobiernos divididos en Baja Cal ifornia está provocando nuevas conductas, posiciones y estrategias de consenso y cooperación entre los poderes ejecutivo y legislativo. Sin embargo, la tendencia observada de parálisis y no cooperación propia de parlamentos con mayorías divididas, debeser corregida con nuevos mecanismos consensuales y legales, de lo contrario, ejercitar la pluralidad y la democracia con una estructura institucional y jurídica desfasada, tendrá un alto costo político. 


\section{BIBLIOGRAFÍA}

Blum Valenzuela, Roberto (1996). Dela política mexicana y sus medios. Deterioro institucional o nuevo pacto político, Miguel Ángel Porrúa, México.

Carrillo, Ulises y Alonso Lujambio. s/ f. "La incertidumbre constitucional. Gobierno dividido y aprobación presupuestal en la LVII legislatura del congreso mexicano, 1997-2000", para ser consultado en internet en la página: http:/ / 132.248.82.108/ rms/ rms298/ carrillo.html

Carpizo, Jorge. 1994. El presidencial ismo mexicano, Siglo XXI, M éxico. Casar, Ma. Amparo (1996). "El presidencialismo mexicano y la estructura deacceso y distribución del poder político", en: Ricardo EspinozaToledo (Cood.), M emorias del Congreso $\mathrm{N}$ acional deCiencia Política, UAM, IFE, Colegio Nacional de Ciencias Políticas y Administración Pública, México.

Casillas, Carlos. s/ f. “Gobierno dividido en M éxico", para ser consultado en internet en la página: http:/ / www.nexos.com.mx/ nexos/ oct250/ temcen/ tema5.html

Espinoza Toledo, Ricardo (coord.) (1996). "Presidencialismo", en: Memorias del Congreso Nacional deCiencia Política. UAM/ IFE/ Colegio Nacional deCiencias Políticas y Administración Pública, México.

Córdova, Arnaldo. 1994. La formación del poder político en México, Era, M éxico.

Espinoza Valle, Víctor A lejandro. 1998. Alternancia política y gestión pública, El Colegio dela Frontera N orte, México.

Guillén López, Tonatiuh. 1993. Baja Cal ifornia, 1989-1992. Alternancia política y transición democrática, El Colegio dela Frontera N orte, México.

Hurtado,Javier. 1998. “Los gobiernos divididos y las elecciones de1998 en México", revista Este país, abril de 1998.

López Villafañe, Víctor. 1993. La formación del sistema político mexicano, Siglo XXı, México. 
Mainwaring, Scott y Matthew Soberg Shugart. “El presidencialismo y Ios sistemas de partido en Latinoamérica", en: La reforma del Estado, UNAM, México.

Romero, Jorge Javier (1996). “La construcción institucional del presidencialismo" en Ricardo Espinoza Toledo (Coord.) Memorias del Congreso Nacional de Ciencia Política, uam, ife, Colegio Nacional deCiencias Políticasy Administración Pública, México.

Rubio, Luis (1994). R eforma al sistema político mexicano, Diana, México. 